of SS were sampled from the factory at different times. The temperature increased to higher than $50{ }^{\circ} \mathrm{C}$ when the SS of wastewater ranged from 3,000 to 4,300 $\mathrm{mg} \cdot 1^{-1}$. This means that such wastewater containing high amounts of SS could be treated by this process while the UASB was not able to treat such wastewater, and the SS should be lower than approximately 3,000 $\mathrm{mg} \cdot 1^{-1} \cdot{ }^{5}$

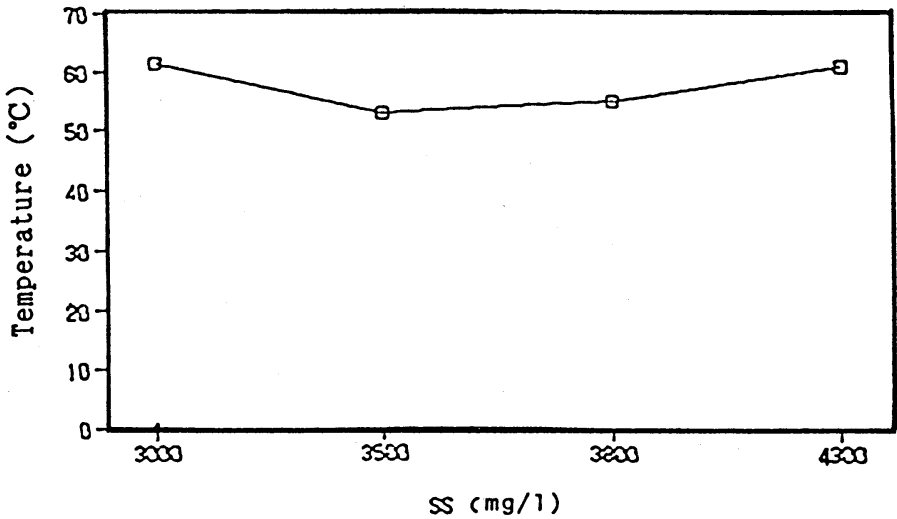

Fig. 6 Effect of SS on Temperature Increase (BOD load: $3 \mathrm{kgBOD} \cdot \mathrm{M}^{-3} \cdot \mathrm{d}^{-1}$ )

\title{
4. Summary
}

The red bean processing wastewater which contained high amounts of organic matter and SS was effectively treated by thermophilic oxic process. As a result of 6 months of experimental operation, the following items became clear:

(1) When BOD loads ranged from 2 to $5 \mathrm{kgBOD} \cdot \mathrm{M}^{-3} \cdot \mathrm{d}^{-1}$ at the aeration rate of $50 \sim 200 \mathrm{\&} \cdot$ $\mathrm{M}^{-3} \cdot \min ^{-1}$, average removal ratios of $\mathrm{BOD}$ and $\mathrm{COD}_{\mathrm{MN}}$ were higher than $94 \%$.

(2) The weights of the absorbant mixed with the wastewater did not change. This means that little excess sludge was formed because most of the organic matter was converted to $\mathrm{CO}_{2}$.

(3) This process can be applicable even if the SS was $4,300 \mathrm{mg} / \mathrm{l}$.

Acknowledgements --- The authors are grateful to Mr. Oya and Yamamoto of Toyoseisakusyo and $\mathrm{Mr}$. Masanari Miura, Mr.Zhu Lieping for their help in conducting the experiment.

\section{REFERENCES}

1. Kiyohiko Nakasaki. 1985. "Effect of Temperature on Composting of Sewage Sludge" Applied and Environmental Microbiology. Vol.50. No.6, Dec.1985, p.1526-1530

2. S.Hashimoto, R.Sudo: "New Activated Sludge Method " Sangyo Yosui Chosakai 1986.9 p.1-40.

3. R.Sudo: "Wastewater Treatment by Immobilized Microorganisms " Sangyo Yosui Chosakai 1988.9 p. 220-276.

4. D.Couillard. "Slaughterhouse Effluent Treatment by Thermophilic Aerobic Process" Wat.Res.Vol. 23 ,No.5, pp.573-579, 1989

5. Hideki Harada: Private communication, 1992.

6. Tadahiro Mori. et.al. Soil Sci. Plant Nutr., 27(4),477-486, 1981 " Composting of Municipal Sewage Sludge Mixed With Rice Hulls"

7. Kiyohiko Nakasaki.1985 "Change in Microbial Numbers during Thermophilic Composting of Sewage Sludge with Reference to $\mathrm{CO}_{2}$ Evolution Rate". Applied and Environmental Microbiology. Vol.49. No.1, Jan.1985, p. 37-41

8. Y.Kurihara and T.Mori " Composting Sludge with Reeds". Biocycle. p.38-41, September 1987 


\title{
(10) 活性污泥馝濁液の膜分離における透過フラックスに関する研究 STUDY ON PERMEATION FLUX OF ACTIVATED SLUDGE SUSPENSION IN ULTRA MEMBRANE FILTRATION
}

\author{
西村和之* 河村清史*、真柄泰基*
}

Kazuyuki NISHIMURA*, Kiyoshi KaMAMURA*, Yasumoto MAGARA*

\begin{abstract}
Operational conditions, in solid-liquid separation, of a cross-flow type ultra membrane filtration system were examined to make clear the mechanism of water permeation. Activated sludge suspension was applied as a model sample, and a flat plate type module with different section areas and a tubular type module were used in the experiments.

In the both modules, the permeation flux is shown by the experimental equation obtained, which considers the effects of module pressure on membrane resistance $(\mathrm{Rm})$ and applies the cake filtration to the resistance(Rcg) caused by cake-layer and/or gel-layer.

The effects of flow velocity to Rcg are evaluated more effectively by shear stress $\left(\begin{array}{l}\tau \\ \tau_{0}\end{array}\right)$ than flow velocity itself and Reynolds number. From the relationships between $T_{0}$ and Rcg, the filtration is classified into 3 types as follows; 1)filtration with predominance of membrane filtration, 2)filtration with predominance of cake filtration, and 3)filtration with mixed effects of the both.

In the flat plate type module, at low MLSS concentrations, the filtration types 1) and 2) are observed and the critical values of To are around $500 \mathrm{kPa}$. And at high MLSS concentration, the types 1 ) and 3) are observed and $\mathrm{T} 0$ of about $500 \mathrm{kPa}$ is critical. On the other hand, in the tubular type module, only the types 1) and 2) are observed at low and high MLSS concentrations and the critical values of $\mathrm{T}_{0}$ are about $1000 \mathrm{kPa}$ in the both cases. KEYWORDS; UItra membrane filtration, Operational factors, Permeation flux, Cake resistance, Gel resistance, Shear stress
\end{abstract}

\section{1.はじめに}

し尿処理においては、高負荷脱窒素処理方式に膜分離技術を導入した膜分離生物脱窒素処理技術が開発 され、平成 3 年に（社）全国都市清掃会議により指針外技術として評価・認定を受けている。この例に見 るように、膜分離プロセスは技術開発の段階から応用・普及の段階に達している。しかしながら、膜分離 プロセスをより効率的なものとするためには、未だ検討すへき課題が多い。

筆者らは、膜分離プロセスのろ過条件が透過フラックスに及ぼす影響を実験的に把握し、ろ過にかかわ る諸因子の影響を定量的に評価することを目的としてケーキろ過式の導入を行った1）。その結果、膜面流 速が一定の場合、各種試料におけるモジュール圧力と透過フラックスとの関係が、膜面上に形成するろ過 抵抗層の重量や圧縮性の違いにより説明できることを示した。しかしながら、膜面流速と透過フラックス との関係を十分に考察するには至らなかった。

本研究では、活性污泥愻濁液を試料として、透過フラックスに及ぼす操作因子、とくに膜面流速の影響 について検討を加えたので、得られた結果を報告する。

\section{2. 透過フラックス式1)}

クロスフロー型膜分離における透過フラックスは、式(1)により定義される2)3）。

*国立公䋰衛生院 The Institute of Public Health 


$$
\mathrm{J}=\frac{\mathrm{P}}{\eta \cdot \mathrm{R}}=\frac{\mathrm{P}}{\eta \cdot(\mathrm{Rm}+\mathrm{Rcg})}
$$

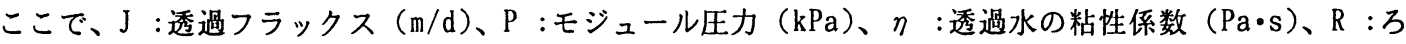
過抵抗 $(1 / \mathrm{m}) 、 \operatorname{Rm}:$ 膜抵抗 $(1 / \mathrm{m}) 、 \operatorname{Rcg}:$ 万過抵抗層（ケーキ首とゲル層を合わせたもの）による抵抗 $(1 / \mathrm{m})$ であるが、Rcgには膜内部での物質の目詰まり抵抗を含めている。なお、モジュール压力は、モジュ ールの入口および出口での圧力の平均值とした。

$\mathrm{Rm}$ につては、Hが 2mmの平膜型モジュールについて、式(2)の実験式を得ている。

$$
\mathrm{Rm}=\mathrm{Rm}_{150} \cdot \mathrm{a}^{(\mathrm{P}-150)}
$$

ここで、Rm150 : $150 \mathrm{kPa}$ における膜抵抗 $(1 / \mathrm{m}) 、 \mathrm{a}:$ 係数(一)である。

Rcgについては、ケーキろ過式を導入すると式(3)で表される。

$$
\operatorname{Rcg}=\alpha \cdot(\mathbb{N} / \mathrm{A})=(\mathbb{W} / \mathrm{A}) \cdot \mathrm{c} \cdot \mathrm{P}^{\mathrm{n}}
$$

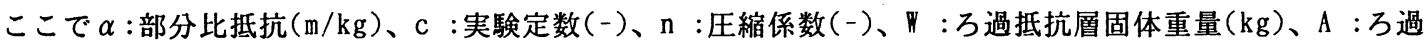
膜全面積 $\left(\mathrm{m}^{2}\right)$ であり、W/Aは単位ろ過面積当りのろ過抵抗層固体重量に相当する。

式(2)および式(3)を式(1)に代入し、 $\mathrm{Rm}_{150}$ を $\mathrm{b} と し 、(\mathbb{A} / \mathrm{A}) \cdot \mathrm{c}$ を $\mathrm{K}$ とすると式(4)が得られる。クロスフ ロ一型膜分離の場合、界/Aが膜面流速に支配されると仮定すると、膜面流速が一定の条件では透過フラック スは式(4)よりモジュール圧力の関数となり、処理対象水中成分の特性值である nの值でモジュール圧力と 透遇フラックスとの関係を説明することができる。

$$
\mathrm{J}=\frac{\mathrm{P}}{\eta \cdot\left\{\mathrm{b} \cdot \mathrm{a}^{(\mathrm{P}-150)}+\mathrm{K} \cdot(\mathrm{P}-150)^{\mathrm{n}}\right\}}
$$

\section{3. 実験方法}

\section{1 実験装置}

実験装置を図-1に示す。膜モジュールとして、平膜型モジュールとチューブラー型モジュールを用いた。 平膜型モジュールでは、膜面上のモジュール内流路高さHを変化させることにより、流路断面積を 3 段階 に変化させて実験を行った。各モジュールの仕様を表-1にまとめる。

\section{2 試料}

実験には、精製水と活性污泥慜濁液( ス キムミルクを基質として培養した活性污泥 を精製水で洗浄し、精製水に再䡈濁させ $\mathrm{pH} 7.2$ に調整したもの)を試料として用 いた。

\section{3 実験条件}

操作圧力はポンプの吐出圧と窒素ガスに よる加圧力との合算値である入口側圧力で 制御し、膜面流速は循環流量を変えること により制御した。なお、膜面流速は、モジ ュール流路断面積から計算される断面平均 流速を用いた。また、試料水温は、図一1に

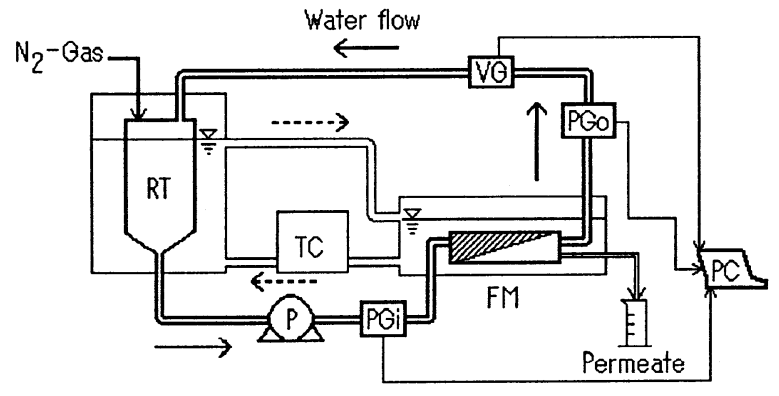

FM: Filter module RT: Raw water tank $P$ : Pump TC: Temperature controlar PC: Personal computer

Fig. -1 Schematic diagram of experimental cross-flow filtration system 
実験は、同一の膜及び試料を用いて種々の圧力と膜面流速の組み合せの下で透過フラックスのデータを 得ることとした。このため、実験時間内で膜の性状や試料の変質が透過フラックスに与える影響が大きく ならないよう、各組み合わせの下での実験時間は 5 分間とした。

実験条件の設定は、モジュールを接続し、原水タンクに試料を入れ試料温度を調整することにより行っ た。操作条件は、膜面流速を設定し、室素ガスにより入口圧力を調整することにより設定した。透過つ ラックスは、条件設定後装置が安定した後の 5 分間の内 2 分目から 4 分目の間に流出したろ液量から算出 した。

ろ過膜は、試料毎に新しい膜 Tab.-1 Ultra filter and filter module used in the experiments に交換し、その都度操作圧力 $392.3 \mathrm{kPa}$ 、循環流量 18 $\mathrm{L} / \mathrm{min}$ ( $\mathrm{H}$ が $2 \mathrm{~mm}$ の平膜型モジ ュールの場合、膜面流速として $3.6 \mathrm{~m} / \mathrm{s}$ )の操作条件で 1 時間 精製水を透過させることによっ て、ろ過膜のスポンジ層を圧密 させる前処理を行った。また、 試料の粘性係数は回転式粘度計

\begin{tabular}{|c|cc|}
\hline & Flat plate type & Tubular type \\
\hline Filter material & Polysulfone & Polysulfone \\
Cut off poit (M. W. ) & $2,000,000$ & 20,000 \\
Filter ares (m²) & 0.0336 & 0.034 \\
Section area $\left(\mathrm{m}^{2}\right)$ & Type I $0.04 \times 0.002$ & $0.0001038(\phi 11.5 \mathrm{~mm})$ \\
(II (m) $\times$ H (m)) & Type II $0.04 \times 0.003$ & \\
& Type III $0.04 \times 0.005$ & \\
\hline
\end{tabular}

で測定し、密度は比重計により求めた比重から計算した。

\section{4. 実験結果および考察}

4. 1 平膜型モジュールにおける活性污泥懸濁液の実験

平膜型モジュールにお けるモジュール压力と透 過フラックスとの関係を 図-2に示す。図中の実線 は、膜面流速が1.2,2.4, $3.6 \mathrm{~m} / \mathrm{s}$ の条件について $\mathrm{n}$ と $(\mathbb{T} / \mathrm{A}) \cdot \mathrm{c}$ を求め、式 （4）を用いて得たモジュ 一ル圧力と透過フラック スの関係を示したもので ある。

膜面流速が一定の場合 のモジュール圧力と透過 フラックスの関係は、試 料のSS濃度や膜面流速に より異なっている。すな わち、図-2 a, bに示す ようにSS濃度が $6000 \mathrm{mg} / \mathrm{L}$ 以下の場合、モジュール 圧力が低い領域では透過

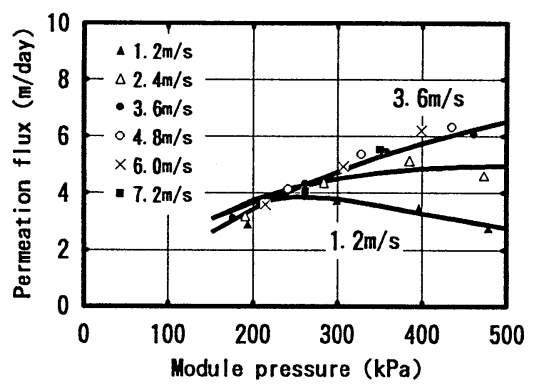

a: (SS: $5760 \mathrm{mg} / \mathrm{L}, H: 2 \mathrm{~mm}$ )

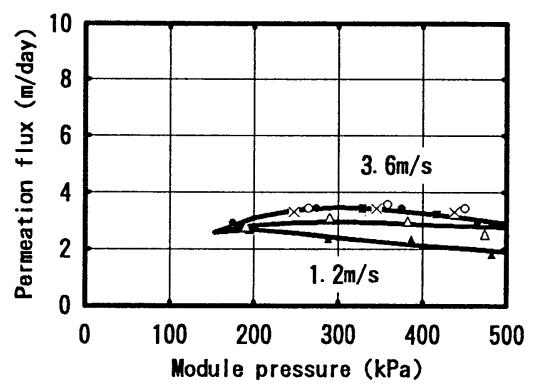

c: (SS: $7533 \mathrm{mg} / \mathrm{L}, \mathrm{H}: 5 \mathrm{~mm}$ )

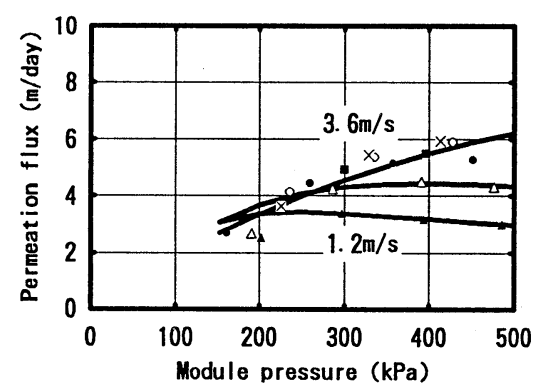

b: (SS: $4749 \mathrm{mg} / \mathrm{L}, \mathrm{H}: 3 \mathrm{~mm}$ )

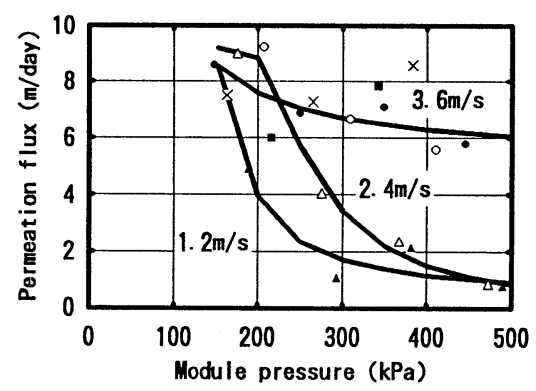

d: (SS: $16650 \mathrm{mg} / \mathrm{L}, \mathrm{H}: 2 \mathrm{~mm}$ )

Fig. - 2 Relationship betwen module presure and permeation flux of A. Sludge suspension in the flat plate type module 
フラックスはモジュール圧力の増加とともに增加するが、さらに大きなモジュール圧力が加わるとモジュ 一ル圧力の增加とともに低下する。また、図-2cのようにSS濃度が高くなった場合でも、顕著ではないが この傾向が認められる。一方、図-2 dのようにSS濃度が $16650 \mathrm{mg} / \mathrm{L}$ と大き場合には、膜面流速にかかわ らず、透過フラックスはモジュール圧力の增加とともに減少する傾向が認められた。

この様に、膜面流速が一定の場合、モジュール圧力と透過フラックスの関係は多様であるが、これらは 式(4)による計算值とよく合うことから、Hの值やSS濃度にかかわらず、膜面流速の影響を受けると考えら れる(N/A) と圧力の影響を表す $\mathrm{n}$ 唀過フラックスを支配する大きな因子であるといえる。

\section{2 チューブラー型モジュールにおける精製水および活性污泥矁濁液の実験}

精製水を試料として用いたチューブラー型モジュール による実験の結果、いずれの膜面流速でもモジュール圧 力が低い領域では透過フラックスはモジュール圧力の增 加とともに增加するが、さらに大きくなると透過フラッ クスはほとんど変化しなくなり、それぞれの膜面流速で の最大值となった。この実験結果を、モジュール圧力と 膜抵抗との関係として表わすと図-3に示すようになり、 膜抵抗はモジュール压力の增加と共に増加した。

これらのことから、チューブラー型モジュールにおい ても平膜型モジュールと同様に、前処理により予め膜の 圧密調整を行ってはいるが、実験により加圧されると膜

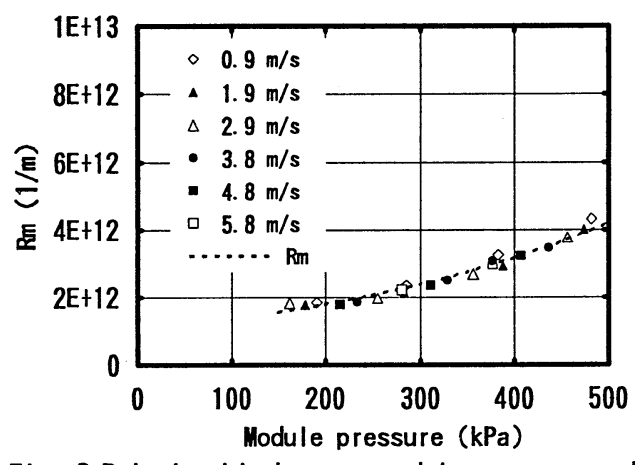

Fig. -3 Relationship between module pressure and filter resistance of pure water (NTU-3520) のスポンジ層はさらに圧密し、膜抵抗の增加をむたらすものと考えられる。チューブラー型モジュールに おいても式(2)が成り立ち、実験結果より $\mathrm{a}=1.0028$ 及び $\mathrm{Rm}_{150}=1.56 \times 10^{12}(1 / \mathrm{m})$ を得た。

本研究では、同一試料の 実験は同一膜を用いて行っ ており、膜のくりかえし使 用による液中成分の膜への 影響を取り除くことができ ないことから、以下の検討 におけるRmは、実験的に 求めることなく式(2)によ り定めることとした。すな わち係数 aは $1.0028 て ゙ 一$

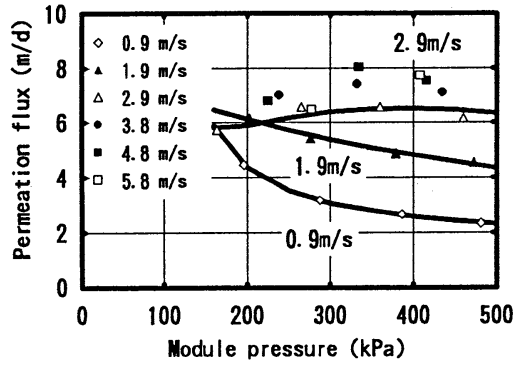

a: (SS: $6407 \mathrm{mg} / \mathrm{L}$ )

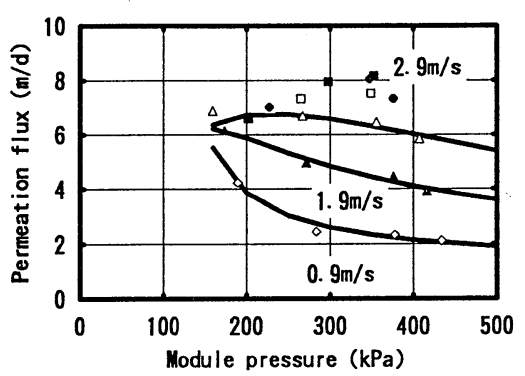

b: (SS: $19330 \mathrm{mg} / \mathrm{L}$ )
Fig. -4 Relationship between module presure and permeation flux of A. sludge suspension in the tubular type module

定とし、 $\mathrm{Rm}_{150}$ は膜毎に異なると考え、初期化直後に一条件で測定した精製水透過フラックスと式(2)及び aを用いて $\mathrm{Rm}_{150}$ を求め、これらを用いて任意のモジュール圧力におけるRmを求めた。

活性污泥愻濁液を試料として用いた場合のモジュール圧力と透過フラックスの関係を図-4に示す。図中

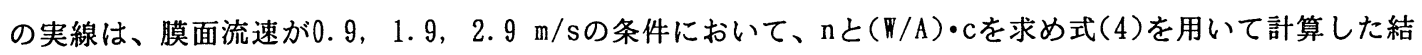
果を表わしている。

モジュール圧力と透過フラックスとの関係は、SS濃度や膜面流速により異なるが、平膜型モジュールで の結果と同様の傾向が認められる。また、式(4)による計算結果は実験結果とよく合うことから、チューブ ラー型モジュールにおいても平膜型モジュールと同様にケーキろ過式が適用できると言える。 